\title{
Solvent-free microwave extraction of bioactive compounds provides a tool for green analytical chemistry
}

\author{
Ying Li, Anne Sylvie Fabiano-Tixier, Maryline Abert Vian, Farid Chemat
}

\begin{abstract}
We present an overview on solvent-free microwave-extraction techniques of bioactive compounds from natural products. This new technique is based on the concept of green analytical chemistry. It has proved to be an alternative to other techniques with the advantages of reducing extraction times, energy consumption, solvent use and $\mathrm{CO}_{2}$ emissions.
\end{abstract}

Keywords: Bioactive compound; $\mathrm{CO}_{2}$ emission; Energy consumption; Extraction time; Green analytical chemistry (GAC); Microwave hydro-diffusion and gravity (MHG); Natural product; Sample preparation; Solvent-free microwave extraction (SFME); Solvent use

\section{Introduction}

Ying Li,
Anne Sylvie Fabiano-Tixier,
Maryline Abert Vian,
Farid Chemat*
Université d'Avignon et des
Pays de Vaucluse,
INRA, UMR 408, F-84000
Avignon, France

"Corresponding author. Tel.: $+33 \quad 4901444$ 65; Fax: +33 $490 \quad 14 \quad 44 \quad 41$; E-mail: Farid.Chemat@ univ-avignon.fr in different analytical fields (e.g., environmental and agricultural sectors, and the cosmetics, food and pharmaceutical industries).

Microwave is a non-contact heat source, which can not only make heating more effective and selective, but also help to accelerate energy transfer, start-up and response to heating control and to reduce thermal gradient, equipment size and operation units [12]. Microwave-assisted extraction (MAE) is a key, sustainable technology in achieving the objectives of GAC. It has been rapidly developed as one of the hot-spot techniques for isolating interesting high added-value compounds from solid samples. With the help of microwaves, extraction or distillation can now be completed in minutes instead of hours with various advantages (e.g., high reproducibility, less solvent and energy consumption, more compact procedures, and greater purity of the final product). Several classes of compounds (e.g., essential oils, antioxidants, pigments, aromas, and other organic compounds) have been separated efficiently from raw materials, particularly natural-plant resources.

Due to the growing concern for the impact of petroleum-based solvents on the environment and the human body, a greener technique, namely solvent-free microwave extraction (SFME), was developed in recent times with considerable 
success in line with the same principles as MAE. The obvious benefits of using SFME are reduction of pollution and handling costs, as the result of the simplified manipulation procedure, easy clean-up and labor saving. These would be especially important considerations in both laboratory and industry.

This article gives an overview of current knowledge on SFME of bioactive compounds from natural products. We discuss the necessary theoretical background, the main up-to-date devices, their mechanisms, parameters, applications, and safety and environmental considerations on sample preparation before natural-product analysis.

\section{Mechanism and parameters of SFME}

For SFME, in-situ water in plant cells is stimulated to rotate under microwave irradiation, so immediate internal change results in a subsequent pressure increase inside plant cells, which leads to break down of cell walls and release of target molecules (Fig. 1).

SFME allows mass and heat transfer from inside the plant cell to the outside, while these two transport phenomena are in the opposite direction in conventional separations. This significant difference makes the temperature increase in much shorter time due to the volumetric heating effect, depending on the microwave power and the dielectric loss factor of the material being irradiated. In order to understand the phenomena of microwave extraction well, scanning-electron microscopy (SEM) was used to observe the behavior of plant cells (Fig. 2). Moreover, the physical changes in the plant tissues distinguishable between SFME and conventional methods have been demonstrated by more SEM studies [13,14]. The cell and cell walls of plants are strongly disrupted to different degrees after SFME at $100^{\circ} \mathrm{C}$. However, the plant tissues subjected to hydrodistillation (HD) appeared very similar to untreated materials. This indicates that the mechanical strain induced by the rapid decompression and the violent vaporization of water have two main effects:

(1) the dehydrating effect due to vaporization; and,

(2) a subsequent change in the surface tension of the glandular wall, causing it to crumble or rupture more readily.

Similar effects were also found in the tissue of other plants treated by microwave steam distillation (MSD) and microwave steam diffusion (MSDf) [15-17]. The pronounced damage in all plant tissues and a homogenous cell wall alternation were revealed in all these SFME cases, which also resulted in more extracts released more rapidly than in conventional extraction.

Water content of the natural plant materials, microwave power and extraction time are also influencing parameters for yield of bioactive compounds. Since water is an excellent absorber of the microwave energy, the water content of sample under a microwave treatment plays an important role in SFME separation. This strong absorption provides the temperature increase inside the sample, which leads to the expansion and the rupture of the cells by the in-situ water.

The required microwave input power is directly related to sample size and weight. The power must be sufficient to reach the boiling point of the water $\left(100^{\circ} \mathrm{C}\right)$, which fixes the extraction temperature. However, the power should not be too high, otherwise loss of volatile compounds and degradation of bioactive compounds would occur. Extraction time is also a major factor directly affecting the yield of extracts using SFME. The yield increases almost linearly as time increases. Considering the maximization of the extraction yield without damaging the quality of extracts, the water content, microwave power and extraction time, and other potential operating parameters, are usually optimized by response-surface methodology (RSM) before start-up $[14,17]$. Generally, the efficiency of SFME, in terms of yield and composition of the extracts, can be optimally performed by increasing the operating factors. The optimal values corresponding practically to the experimental results in natural product analysis have proved SFME itself to be economically and environmentally viable.

In addition, the boiling point of bioactive compounds is not the determining factor for yield and composition of extracts during SFME because hydrocarbons and oxygenated compounds present in the essential oil have been distilled at the same temperature $\left(100^{\circ} \mathrm{C}\right)$ no matter what their own boiling points [18-23]. Besides, better knowledge of the solubility and the polarity of compounds inside natural plants is a more direct way to understand the composition of the extracts from SFME methods. The compounds extracted depend on their solubility in water rather than the order of their boiling points. It would also be reasonable to believe that the more polar the compounds, the more readily the microwave irradiation is absorbed, the better the interaction between the electromagnetic wave and matter is established, and the higher the more polar aromatic component contents are obtained.

\section{Techniques and instruments}

It has been proved that solvent-free reactions are successfully coupled to microwave-assisted organic synthesis, as reactions can proceed safely under atmospheric pressure in the presence of significant amounts of product [24]. SFME has been conceived according to the concepts of solvent-free microwave synthesis. When combined with microwave radiation, solvent-free techniques have performed as economic, eco-friendly 
Version définitive du manuscrit publiée dans / Final version of the manuscript published in :

Trends in analytical chemistry (2013), Vol. 47, p. 1-11, DOI: 10.1016/j.trac.2013.02.007

Journal homepage: http://www.sciencedirect.com/science/article/pii/S0165993613000721\#
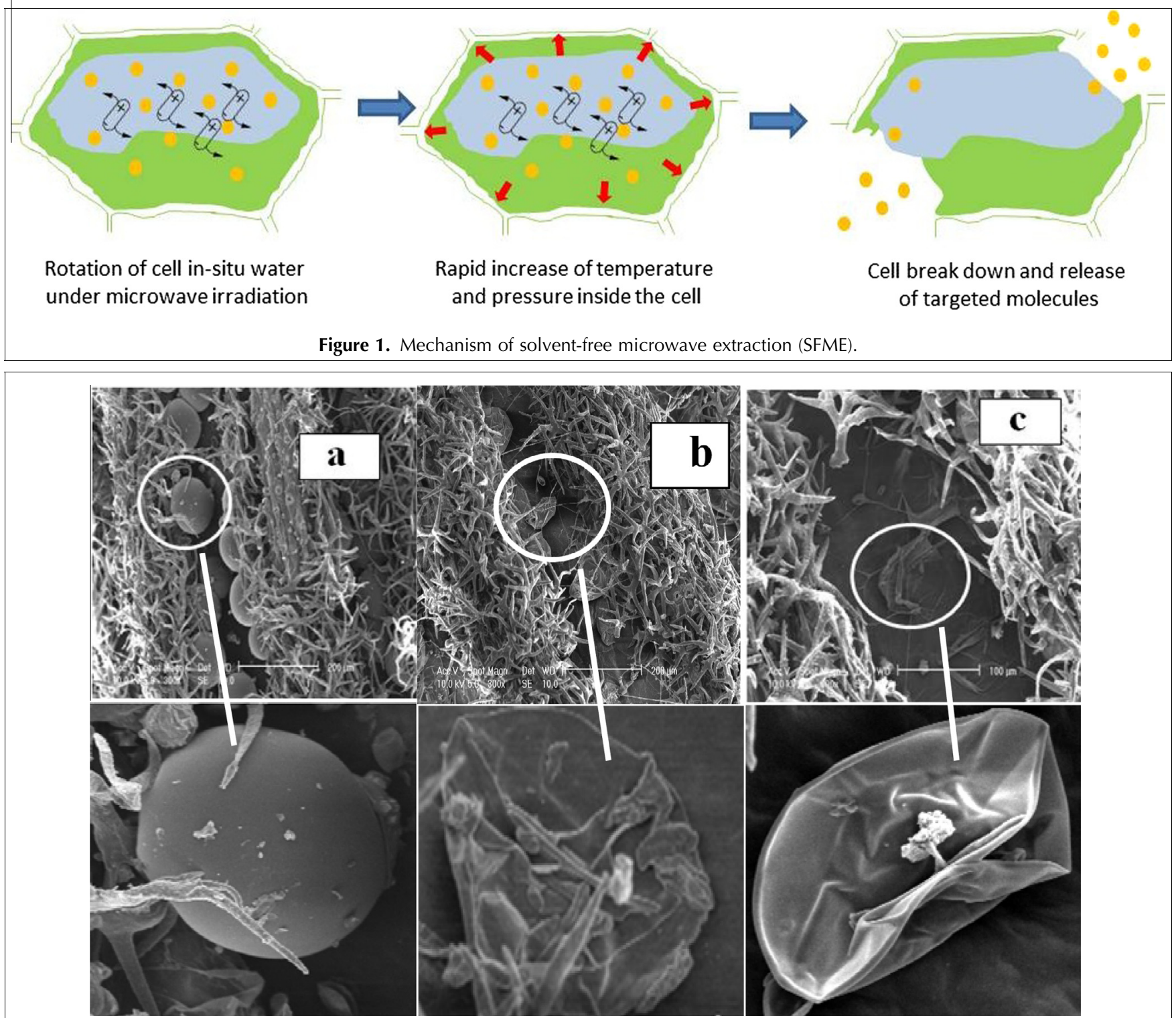

Figure 2. The structure of lavender flowers observed by SEM: (a) before extraction; (b) after microwave extraction; and, (c) after conventional extraction.

procedures with special efficiency. Major improvements and simplifications over conventional methods originate from their rapidity, enhancement of their yields and high-quality products. SFME extends from analytical scale to industrial applications for laboratory or commercial purposes.

\subsection{SFME}

The first SFME technique for extracting natural products was developed by Chemat et al. in 2004 [25,26]. Based on a relatively simple principle, this method involved placing vegetable material in a microwave reactor without addition of any solvent or water. Fig. 3 shows this SFME apparatus. The internal heating of the in-situ water within the plant material distends the plant cells and leads to rupture of the glands and oleiferous receptacles. Thus, this process releases essential oils containing bioactive compounds, which are evaporated by the in-situ water of the plant material. A cooling system outside the microwave oven allows the continuous condensation of the distillate, which comprises water and essential oils. The excessive water is refluxed to the reactor in order to maintain the proper humidity rate of the plant materials.

All the laboratory-scale experiments can be conducted at atmospheric pressure without solvent or added water. The operating parameters, which need to be optimized, can be easily controlled. The essential oils are finally collected, dried with anhydrous sodium sulfate and stored at low temperature for further analysis by gas 
chromatography coupled with mass spectrometry (GCMS) or other analytical methods.

\subsubsection{Improved SFME (ISFME). ISFME was proposed by Wang et al. in 2006 [27]. The method depends on the use of SFME, in which microwave-absorption medium (MAM) (e.g., carbonyl iron powders) are added and mixed with dry matrix at the bottom of the reactor. The spherical particles of MAM are able to absorb part of the emitted microwave energy and store it as heat. Thus, the matrix can be heated by simple conduction without any auxiliary energy. Different types of material [e.g., graphite powders, activated carbon powders, and ionic liquid (1-hexyl-3-methylimidazolium hexafluorophos- phate)] can be used as the MAM in ISFME systems due to their excellent microwave-absorption properties and good chemical stability [28,29].}

\subsubsection{Vacuum microwave hydro distillation (VMHD).} VMHD was devised by Mompon et al. in 1994 [30]. This technique is based on selective heating by microwaves combined with sequential application of vacuum. The plant materials are placed in a microwave cavity with water to refresh the dry material. The plant materials are afterwards exposed to microwave radiation in order to release the natural extract. Reducing the pressure to 100200 mbar enables evaporation of the azeotropic watervolatile oil mixture from the biological matrix. The procedure is repeated in a stepwise way, so that all the volatile oil from the plant can be extracted [30,31].

VMHD provides yields comparable to those obtained by traditional HD. However, the extraction time is only one-tenth of that required in HD. The thermally-sensitive crude extracts seem to be preserved with VHMD in contrast to conventional methods. Moreover, VMHD is suggested for extracting high-quality natural products at a large scale $[32,33]$.

\subsubsection{Microwave steam distillation (MSD). MSD has} been designed and developed for isolation of essential oils from natural-plant materials prior to component analysis $[15,16]$. The MSD system involves an electrical steam generator and a condenser placed outside the microwave oven, which is connected to a cartridge containing natural-product matrices via Pyrex connecting tubes. The condenser is connected to a receiving Florentine vase, with preferably a separating funnel for continuous collection of condensate essential oil and water. This system presents the advantage that the cartridge containing plant materials can be easily and quickly replaced and cleaned after each cycle of extraction.

The microwave heating and vapor passing through the raw plant materials in the cartridge distend the plant cells and lead to the rupture of the glands and cell receptacles. The steam evaporates and carries the bioactive compounds directly to the condenser and the
Florentine flask. The extraction proceeds continuously until no more extract is obtained. The extract is then collected, dried and stored at low temperature before further analysis.

The experimental results in the laboratory have proved the effectiveness of MSD, which showed substantial benefits over conventional SD. MSD also shows potential to be an advantageous alternative in the analysis or production of bioactive compounds in the food, cosmetics and pharmaceutical industries.

3.1.4. Microwave steam diffusion (MSDf). MSDf was developed for extraction of essential oils from byproducts of natural materials [17]. In a typical MSDf procedure at atmospheric pressure, the natural raw materials that form the packed bed are piled in a cylindrical Pyrex reactor. The saturated steam produced by an electrical steam generator, passes through the packed bed whilst the mixture is continuously heated in a microwave oven. The coupling of microwaves to saturated steam is conducive to the release of bioactive compounds inside the plant-cell tissues. The extracts thus move naturally downwards by gravity to a spiral condenser outside the microwave cavity. After that, the extracts are collected, dried and finally stored at low temperature until analysis. The MSDf process has proved a better extraction method than conventional SD with important benefits.

3.1.5. Pressurized SFME (PSFME). PSFME was proposed and optimized by Michel et al. in 2011 [34]. This innovative technology involves extraction under pressure without addition of any solvents, where microwave energy is absorbed as the heating source of the solvent-matrix mixed solution by internal water of plant materials.

On the basis of the relatively simple SFME principle, vegetable materials are then placed inside a closed vessel without adding any solvent or water and then subjected to microwave irradiation, which allows microwaves to penetrate plant matrices and to interact with polar molecules (e.g., water). The in-situ polar water of fresh plant materials heats immediately above its boiling point, resulting in an internal heating of plant materials that consequently causes a rapid increase of the pressure inside the plant-cell tissues. This pressure rise leads to disruption of the cell walls and release of solutes afterwards. Moreover, repeated heating leads to complete release of water with target compounds outside the plant matrices. Plant tissues are destroyed and appeared completely dehydrated at the end of the extraction procedure. In addition, the polarity and the viscosity of water are lower at high temperature (around $180^{\circ} \mathrm{C}$ ) under pressure (closed vessel). This pressurized condition makes water dissolve and carry less polar compounds [e.g., flavonol aglycones (non-soluble in water at atmospheric pressure and at room temperature)] out of the 


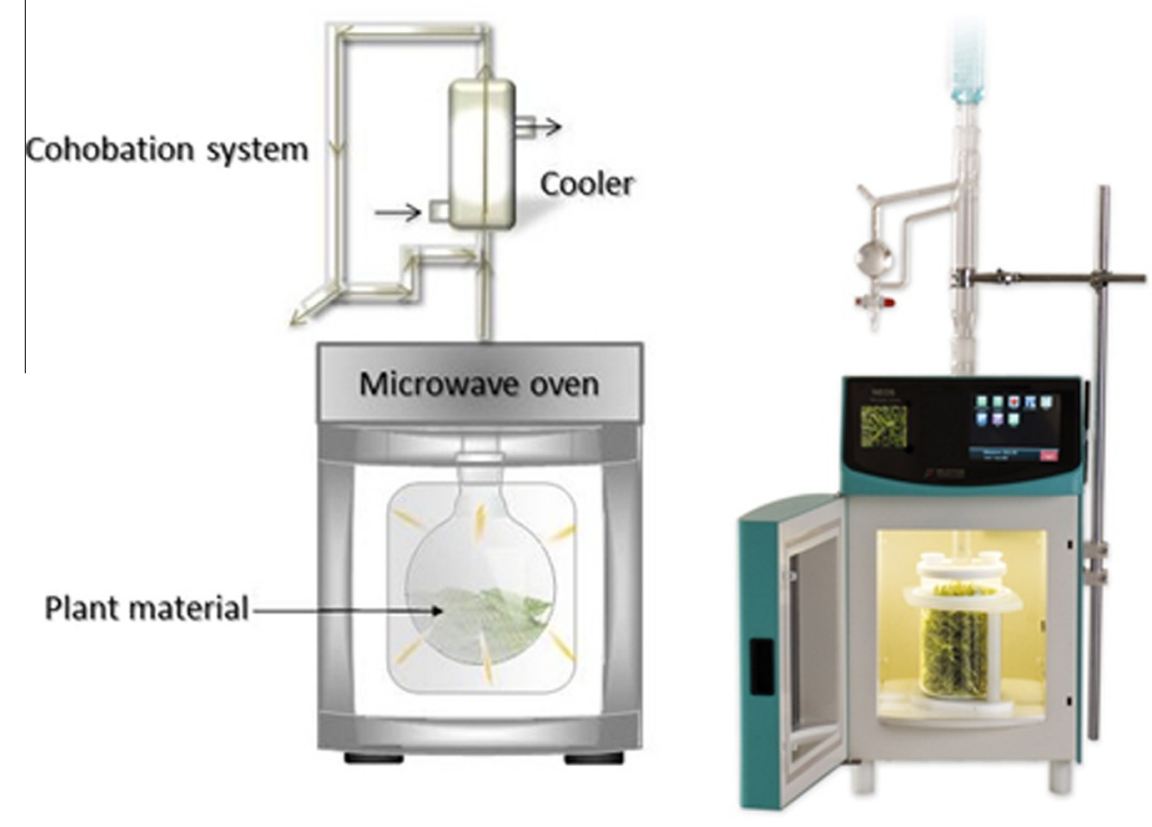

Figure 3. Solvent-free microwave extraction (SFME).

plant matrices. Extracts are finally collected and can be directly used for analysis without a complementary evaporation step. We need to mention that PSFME strongly depends on the moisture of plant materials, so it needs fresh plant materials with sufficient humidity (average moisture 70-80\%) [20,35,36].

Fig. 4 shows PSFME apparatus. Microwave power and irradiation time were controlled during extraction. A fiber optic inserted directly into the vessel and an infrared external sensor were applied to monitor and control temperature inside and outside the reactor, respectively. A 50-mL reactor vessel suitable for microwaves was used as the container for plant materials with no pretreatment, and a stir bar, unable to absorb microwaves, was also introduced. All extracts collected were filtered and diluted for further analysis, depending on the experiments. Before another extraction cycle, the heated vessel was cooled in ice to attain a temperature of $20-25^{\circ} \mathrm{C}$ before the next cycle.

The parameters that may affect the extraction and have to be optimized are: time of microwave irradiation (10-50 s), microwave irradiation power (200-1000 W) and number of extraction cycles (1-5 cycles). The impact of each factor has been methodologically and experimentally studied. The vessel cooling time between each cycle is quite long (several minutes) and that increases the total extraction time. Irradiation time should be appropriately adjusted in line with the increase of temperature and pressure inside the reactor. High temperature (up to $180^{\circ} \mathrm{C}$ ) and pressure inside the reactor simultaneously increased at the end of a 50-s extraction cycle with a $1-\mathrm{kW}$ irradiation power. Because higher temperature or overpressure inside the reactor gives rise to the opening of the vessel-safety membrane - and consequently to the degradation or loss of material - the irradiation time is limited to $50 \mathrm{~s}$ in order to prevent this phenomenon. The number of cycles is a less influential factor - without significant interaction with other factors - but it is the most limiting factor for developing a rapid extraction method. The number of extraction cycles was limited to maximum of cycles so that a reasonable total extraction time could be obtained. The PSFME technique was optimized and applied to extraction of polyphenolic compounds from natural plants.

\subsection{Microwave hydro-diffusion and gravity (MHG)}

MHG is a new, green extraction technique designed by Chemat et al. in 2008 [35]. This extraction technique is an original "upside down" alembic combining microwave heating and gravity at atmospheric pressure. MHG was conceived for laboratory and industrial-scale applications in the extraction of pigments, aroma components, and antioxidants from different kind of plants.

Based on a simple principle, this technique consists of placing plant material inside a microwave reactor, without adding any solvent or water. The heating of the internal water within the plant material allows the destruction of plant cells containing bioactive components. All the possible extracts, including the internal water of the plant, will be released and transferred from the inside to the outside of the plant material. This is the physical hydro-diffusion phenomenon, which allows the extracts to drop out of the microwave reactor under gravity into a cooling system outside the microwave oven 


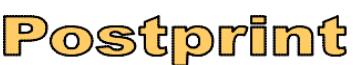

Version définitive du manuscrit publiée dans / Final version of the manuscript published in :

Trends in analytical chemistry (2013), Vol. 47, p. 1-11, DOI: 10.1016/j.trac.2013.02.007

Journal homepage: http://www.sciencedirect.com/science/article/pii/S0165993613000721\#
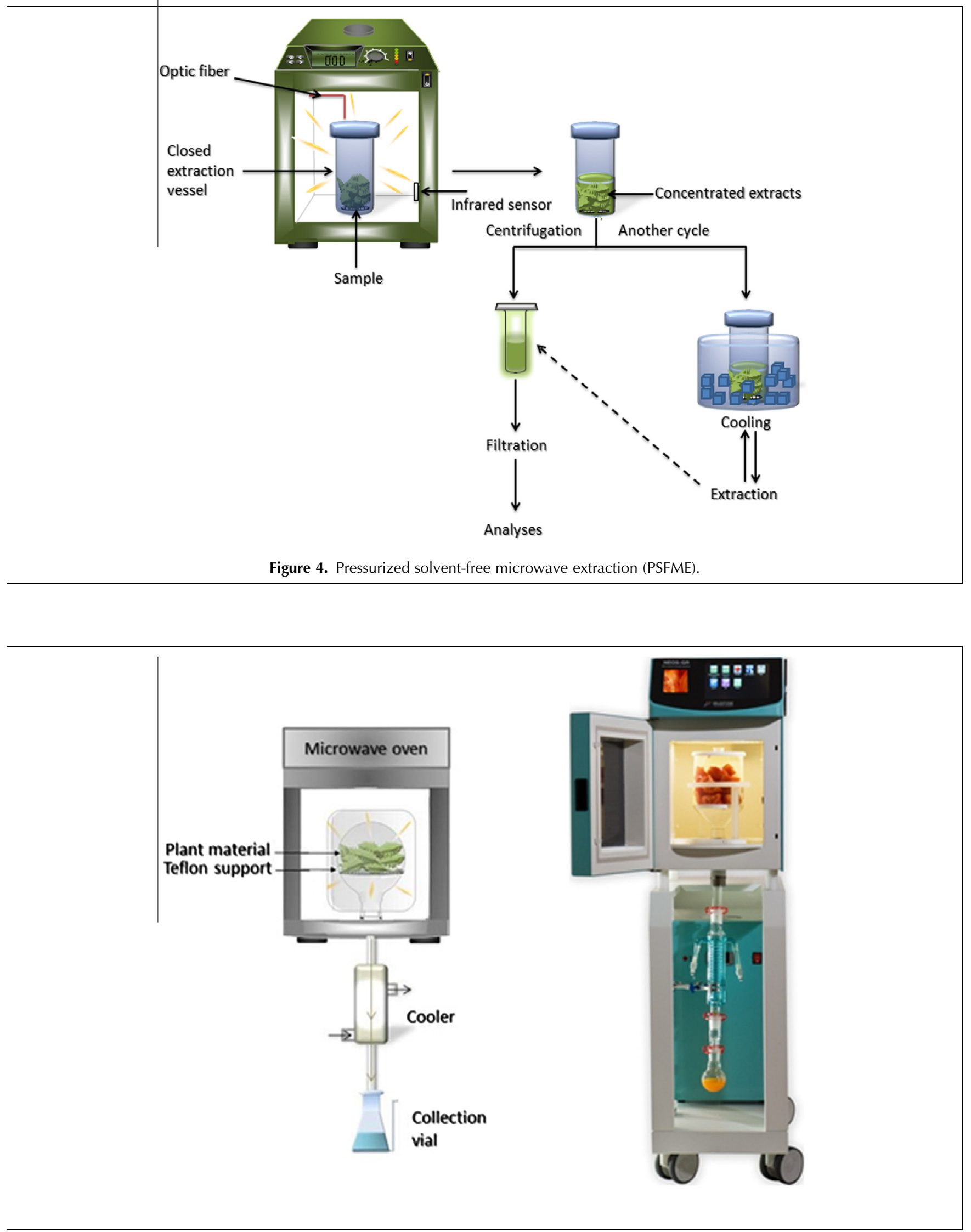

Figure 5. Microwave hydro-diffusion and gravity (MHG). 
Version définitive du manuscrit publiée dans / Final version of the manuscript published in :

Trends in analytical chemistry (2013), Vol. 47, p. 1-11, DOI: 10.1016/j.trac.2013.02.007

Journal homepage: http://www.sciencedirect.com/science/article/pii/S0165993613000721\#

through the perforated Pyrex disc, where the extracts are continuously condensed. The crude extracts are collected in a receiving flask for further analysis (Fig. 5).

The MHG system was later modified by introducing vacuum that is created in the system by a pump. The vacuum pump is fitted between the condenser and the flask that is used to collect natural-plant extracts. The crude extracts are collected and freeze-dried before further analysis [37]. It is important to note that this method allows extraction of bioactive components without distillation and evaporation, which are the most energy-consuming processes. MHG is not modified MAE, which uses organic solvents, nor SFME, which evaporates the bioactive extracts with the in-situ water, or modified HD, which uses a large quantity of water in consuming energy.

3.2.1. Microwave dry-diffusion and gravity (MDG). It is certain that processes related to MHG and MSD offer several remarkable benefits, especially through speed and energy savings. However, both these systems needed the presence of water (e.g., in-situ water for MHG and steam for MSD and MSDf). It was therefore interesting to develop MDG, which was inspired by these methods, for extraction from dried plant materials in the absence of water or solvent. MDG has nearly the same mechanism as described above, including experimental set-up and condition parameters. The highlight is the direct interaction of microwaves with dried plant material. The extracts were collected, dried and stored at low temperature until analyzed. MDG is an attractive novel extraction technology for its high efficiency, completed in minutes without any solvent or water, along with its additional advantages (e.g., higher purity of the final product, simplified manipulation procedures, and no need for post-treatment of wastewater) [38].

\section{Application of SFME in natural-products analysis}

SFME, which proved to be significantly faster, has been sprung up and developed into an alternative laboratoryscale sample-preparation method for natural-products analysis in recent years. One typical example showed that the SFME technique could remarkably reduce 3-h extraction time to only $15 \mathrm{~min}$ but achieve similar yields to those obtained by conventional methods (Fig. 6). The following sub-sections elaborate the application of SFME to flavors and fragrances, antioxidants, natural food colors, presenting the types of sample and analyte extracted in each case and some features of the methods. We comment on the different applications of each device.

\subsection{Flavors and fragrances}

The chemicals responsible for the natural flavor or fragrance are organoleptic compounds that are present at various concentration levels in certain parts of plants (e.g., leaves, flowers, root, or peel). Recovery of flavor and fragrances from their sources is crucial due to their short life span. Conventional methods for extracting flavor and fragrances are less useful, due to their drawbacks (e.g., low yields and by-product formation because of the low stability of target compounds). Besides, the analysis of numerous bioactive constituents is limited [39]. For conventional SD and HD methods, the aromas evaporate with the steam, which percolates through the flask containing the aromatic plants. However, elevated

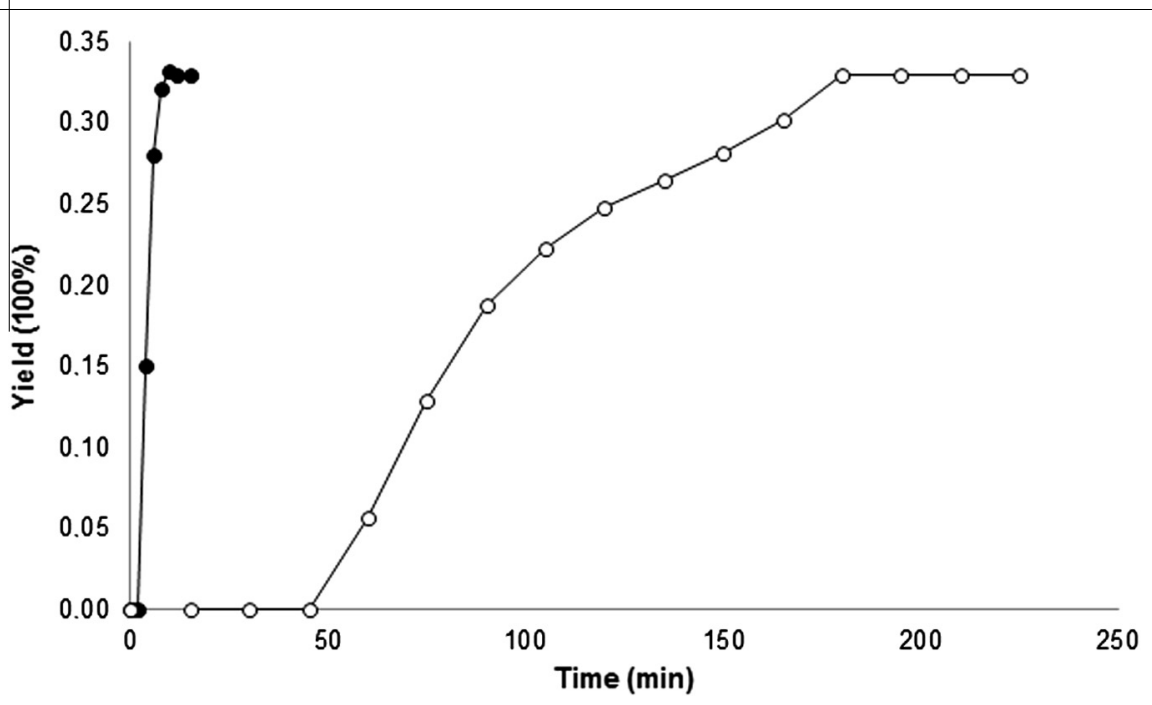

Figure 6. Yields as a function of time for extractions of essential oil from rosemary leaves by microwave hydro-diffusion and gravity (MHG) and hydro-distillation $(\bigcirc)$. 
Version définitive du manuscrit publiée dans / Final version of the manuscript published in :

Trends in analytical chemistry (2013), Vol. 47, p. 1-11, DOI: 10.1016/j.trac.2013.02.007

Journal homepage: http://www.sciencedirect.com/science/article/pii/S0165993613000721\#

Table 1. Applications of solvent-free microwave extraction (SFME) to analysis of bioactive compounds

\begin{tabular}{|c|c|c|}
\hline Material & Technique & Analysis \\
\hline Orange peel & SFME & GC-MS, GC-FID, SEM \\
\hline Cardamoms seeds & SFME & GC-MS, SEM \\
\hline Lavender flowers & MSD & GC-FID, GC-MS, SEM \\
\hline Orange by-product & MSD & GC-FID, GC-MS, cytology \\
\hline Orange peel & MSDf & $\begin{array}{l}\text { GC-FID, GC-MS, } \\
\text { cytohistology }\end{array}$ \\
\hline Lavender flowers & SFME & GC-MS \\
\hline $\begin{array}{l}\text { Aerial parts of Origanum } \\
\text { plant }\end{array}$ & SFME & $\begin{array}{l}\text { GC-FID, GC-MS, } \\
\text { antimicrobial screening }\end{array}$ \\
\hline Aromatic herbs & SFME & GC-MS \\
\hline Orange peels & SFME & GC, GC-MS, proton NMR \\
\hline Rosmarinus officinalis L. & SFME & $\begin{array}{l}\text { GC-MS, antimicrobial } \\
\text { activity testing }\end{array}$ \\
\hline Oregano & SFME & GC-FID, GC-MS \\
\hline
\end{tabular}

O. glandulosum Desf.

SFME

Capillary GC, GC-MS, antimicrobial screening

Cuminum cyminum L. and Zanthoxylum bungeanum

Maxim.

Illicium verum Hook. f. and Zingiber officinale Rosc.

Sea buckthorn (Hippophaë

rhamnoides L.)

M. spicata $L$. and $M$.

pulegium $\mathrm{L}$.

Onion (Allium cepa L.)
PSFME

ISFME

GC-MS

ISFME

GC-MS

MHG

GC-FID, GC-MS

HPLC, DPPH and reducing power test,

MHG
Highlighted analytical results

Ref.

Higher yield of limonene (76.7\%) and

oxygenated compounds (11.7\%).

Higher amounts of oxygenated compounds,

such as 1,8 -cinol and $\alpha$-terpinyl acetate.

Similar composition obtained in very short time.

Better sensory properties than the steam distilled essential oil.

Higher yield of essential oil obtained in shorter time.

Similar composition and yield obtained in shorter time.

Higher yield of oxygenated compounds

$(87.4 \%)$ i.e. thymol $(81.1 \%)$; stronger antimicrobial activity against fungi than bacteria.

All three herb extracts (basil, garden mint and thyme) were richer in oxygenated compounds $(82.2 \%, 77.6 \%, 67.1 \%)$.

Linalool as the main oxygenated components was extracted higher than traditional methods.

Higher yield of oxygenated monoterpenes, such as verbenone $(23.79 \%)$. More activity against $E$. coli and $S$. aureus.

The concentration of monoterpene hydrocarbons decreased while that of sesquiterpenes increased with extraction time; no significant difference was found between different extraction methods for each physical property.

Similar composition obtained among different methods; Higher yield of thymol and oxygenated compounds in SFME extracts, which exerted more activity against fungi than bacteria.

Extraction without any pretreatment; Higher yield obtained for different compounds when extraction time and water content were appropriate.

Oxygenated compounds were the primary components of Illicium verum Hook. f. whereas hydrocarbons were the primary components of Zingiber officinale Rosc. PSFME obtained the most active and richest extract in phenolic content including molecules such as quercetin and isorhamnetin not extracted with other common techniques (pressing, maceration and pressurized liquid extraction).

Higher yield of extracts obtained in shorter time; The same number of volatile secondary metabolites was identified in the extracts and similar yields was obtained as that of conventional methods; lower $\mathrm{CO}_{2}$ emission. Shorter extraction time, no solvent or water used, extraction of onion crude juice retaining fresh organoleptic properties with higher phenolic content (58.29 mg GAE/g DW); Significant yield $(81.5 \%)$ with $41.9 \%$ of flavnol content. method 
Version définitive du manuscrit publiée dans / Final version of the manuscript published in :

Trends in analytical chemistry (2013), Vol. 47, p. 1-11, DOI: 10.1016/j.trac.2013.02.007

Journal homepage: http://www.sciencedirect.com/science/article/pii/S0165993613000721\#

\begin{tabular}{|c|c|c|c|c|}
\hline Material & Technique & Analysis & Highlighted analytical results & Ref \\
\hline Onion by-product & VMHG & $\begin{array}{l}\text { HPLC, UV, Folin-Ciocalteu } \\
\text { method, Antioxidant tests, } \\
\text { Cytological studies }\end{array}$ & $\begin{array}{l}\text { More moisture extracted and dry contents } \\
\text { yield at reduced temperature; More } \\
\text { antioxidants (total quercetin content) } \\
\text { extracted in comparison to MHG and CSE; an } \\
\text { efficient procedure for extraction of heat } \\
\text { sensitive plant components. }\end{array}$ & {$[37$} \\
\hline Dried caraway seeds & MDG & GC-MS, SEM & $\begin{array}{l}\text { Similar composition and yield in shorter time; } \\
\text { two main monoterpenes (carvone and } \\
\text { limonene) with equivalent relative amounts } \\
\text { for both methods. }\end{array}$ & {$[38$} \\
\hline Rosemary leaves & MHG & $\begin{array}{l}\text { GC-FID, GC-MS, sensory } \\
\text { analysis, antimicrobial } \\
\text { screening }\end{array}$ & $\begin{array}{l}\text { Higher amount of oxygenated compounds; } \\
\text { high antimicrobial activities and antioxidant } \\
\text { activity; no preliminary step before analysis. }\end{array}$ & {$[40]$} \\
\hline Citrus peels & MHG & $\begin{array}{l}\text { GC-FID, GC-MS, sensory } \\
\text { analysis }\end{array}$ & $\begin{array}{l}\text { Similar composition and yield obtained in } \\
\text { shorter time; The same number of volatile } \\
\text { secondary metabolites in the extracts isolated } \\
\text { by all methods with similar percentages. }\end{array}$ & {$[41]$} \\
\hline $\begin{array}{l}\text { Red, yellow, white and } \\
\text { grelot onion (Allium cepa) }\end{array}$ & $\mathrm{MHG}$ & $\begin{array}{l}\text { HPLC, Folin-Ciocalteu } \\
\text { method, Antioxidant tests, } \\
\text { Cytological studies }\end{array}$ & $\begin{array}{l}\text { The highest antioxidant capacity was } \\
\text { observed for red onion, followed by yellow, } \\
\text { white and grelot onion; MHG remained the } \\
\text { preferred method for flavonoids extraction in } \\
\text { comparison to CSE. }\end{array}$ & {$[42]$} \\
\hline $\begin{array}{l}\text { Sea buckthorn (Hippophaë } \\
\text { rhamnoides) by-product }\end{array}$ & MHG & $\begin{array}{l}\text { HPLC, Folin-Ciocalteu } \\
\text { method, DPPH test }\end{array}$ & $\begin{array}{l}\text { Shorter extraction time, no solvent or water } \\
\text { used; MHG extract shows much higher } \\
\text { phenolic content with greater antioxidant } \\
\text { activity in comparison to CSE. }\end{array}$ & {$[43]$} \\
\hline Sweet berry & SFME & HPLC, MS & $\begin{array}{l}\text { Recovery of } 1.0 \pm 0.3 \mathrm{mg} \text { of cyanidin-3-O- } \\
\text { glucoside and of } 2.0 \pm 0.5 \mathrm{mg} \text { of cyanidin-3- } \\
\text { O-rutinoside from } 200 \mathrm{mg} \text { of dried cherries } \\
\text { crude extract, which represents } 30 \mathrm{mg} \text { and } \\
60 \mathrm{mg} \text { respectively for } 100 \mathrm{~g} \text { of fresh fruit. }\end{array}$ & {$[44]$} \\
\hline
\end{tabular}

temperature and prolonged extraction time can cause chemical modifications of aromatic components and often loss of the most volatile molecules.

The use of SFME prior to analysis has attracted growing interest in recent years because of its noteworthy benefits. Moreover, it can help obtain high-quality extracts from different natural aromatic plant materials, which can be directly analyzed by chromatographic and spectrometric methods without any preliminary cleanup, solvent-exchange or centrifugation steps.

As summarized in Table 1, flavors and fragrances are often extracted with essential oils according to the results of analysis. The major aromatic compounds in the extracted oil depend on the plant species and are present so similar amounts to extracted oil from conventional methods. GC-MS analysis enables precise quantification of volatile compounds in aromatic plant extracts. In most cases, a substantially bigger amount of oxygenated monoterpenes and a smaller amount of monoterpene hydrocarbons are present in the essential oil isolated by SFME in comparison with that extracted with conventional methods $[13,14]$. The essential oils extracted by MSDf, MSD or conventional methods are rather similar in their composition, and the same numbers of volatile secondary metabolites are found in the essential oils
[15-17]. However, the total amount of oxygenated compounds in ISFME essential oil extracted from Zingiber officinale Rosc. was the smallest [27,28]. In addition, the oils obtained by SFME and MHG were more active against microorganisms than the oil obtained through conventional HD methods [19,40]. Essential oil obtained by MHG showed a slightly higher antioxidant activity, due to the higher proportion of oxygenated compounds contained in MHG essential oil [40].

\subsection{Antioxidants}

There is no doubt that natural-plant antioxidants enable rapid scavenging of free radicals, thereby slowing or preventing the oxidative process (e.g., lipid peroxidation, and accumulation of toxic or off-flavor compounds). It is therefore most desirable to know the specific properties of these molecules and their concentrations in natural plants. Conventional extraction techniques (e.g., maceration, mix-stirring or refluxing) require large amounts of solvent, time and energy. In addition, they are often carried out at high temperature or high pressure, which has a negative impact on the general chemical stability of potent antioxidants. Hence, careful manipulation of light, temperature, $\mathrm{pH}$ or other factors is necessary to prevent antioxidant-rich extracts from oxidation. Development of 
SFME techniques can help to get high-quality extracts, which can be directly analyzed without any preliminary preparation steps. The feasibility of SFME techniques in the analysis of antioxidants has been investigated for different natural-plant matrices. PSFME obtained extracts enriched in phenolic compounds with high antioxidant power. Furthermore, it was the only process for extraction of quercetin and isorhamnetin from a small amount of water [34]. In addition, according to the research of Zill-eHuma et al., PSFME extracts of the flavonol content from onion with direct HPLC analysis presented better results than extracts of conventional methods [41,42], as did HPLC quantification of flavonoids extracted by PSFME from by-products of onion and sea buckthorn respectively, along with evaluating their phenolic contents using the Folin-Ciocalteu method and their reducing power using the DPPH (2,2-diphenyl-1-picrylhydrazyl) test [27,43].

\subsection{Natural colors}

Natural plants dominate as the main sources of natural colors, principally because of the occurrence of one or more of the color-compound groups [e.g., carotenoids (which impart red, orange and yellow), anthocyanins (red, purple and blue), chlorophyll (green), flavonoids (impart yellow, red, blue and purple)]. As far as is known about natural colors, it is interesting to find that the majority also display antioxidant activity.

As the result of growing market demand and usage, most colorants and dyes used currently are artificial synthetics, which are suspected of releasing harmful chemicals that have adverse impacts on human health and environment. Although natural colors are well known for their advantages, they are not commercially successful because of some problems (e.g., high solvent consumption, lack of efficient extraction methods, lack of consistency and difficulty in natural-plant collection and clean-up).

The emergence of SFME techniques can overcome the limitations discussed above and help to acquire high-quality extracts. Anthocyanins were efficiently extracted from sweet cherries by SFME, and the following purification was achieved by semi-preparative liquid chromatography, which provided a considerable yield. Moreover, the main anthocyanins in sweet cherries were successfully identified by MS [44].

Zill-e-Huma et al. reported MHG as a novel technique for extracting flavonoids from onion. The plant tissues were strongly disrupted by microwave irradiation through the microscopic observation of extracts, so that target color compounds could be efficiently extracted and detected by GC-MS and other analysis [41,42]. MHG was also applied to extraction of flavonoids from sea buckthorn by-products, producing a little lower yield of flavonol in a very short time $(15 \mathrm{~min})$ in comparison to classic methods but a higher content of reducing compounds contained in MHG extracts [43].

\section{Safety, energy and environmental considerations}

SFME is proposed as an efficient extraction technique suitable for sample preparation prior to analysis of extracts, which avoids the use of large quantities of solvent or water and voluminous extraction vessels. SFME requires only several minutes heating and less than 30-min evaporation of the in-situ water and extracts from the same material. For the energy requirements, SFME needs less than $0.5 \mathrm{kWh}$ for normal performance but conventional methods expend more than $4.5 \mathrm{kWh}$. Regarding environmental impact, the quantity of carbon dioxide calculated to be rejected in the atmosphere is higher in the case of $\mathrm{HD}$ ( $3600 \mathrm{~g} \mathrm{CO}_{2} / \mathrm{g}$ of essential oil) than for SFME (200 $\mathrm{g} \mathrm{CO}_{2} / \mathrm{g}$ of essential oil). These calculations were based on the following assumption: to obtain $1 \mathrm{kWh}$ from coal or fuel, $800 \mathrm{~g}$ of $\mathrm{CO}_{2}$ will be emitted into the atmosphere during combustion of fossil fuel.

The SFME process is simple and can be readily performed with several operating steps. It could be used to produce extracts by using existing microwave reactors, which are suitable for the extraction of fresh plant materials [16]. Moreover, these reactors could be easily modified and used for techniques derived from SFME. However, the application of microwave energy can pose serious hazards to inexperienced workers. Specific standards and attention to detail in planning and conducting experiments must be strictly obeyed by everyone dealing with microwaves. It requires appropriate information from knowledgeable sources and implementation of SFME techniques with proper guidance. Only approved equipment and scientifically sound procedures should be used at all times [45].

\section{Conclusion and future trends}

SFME techniques have been constantly improved directly by putting increasing knowledge directly into technical practice to achieve commercial development. SFME makes use of physical and chemical phenomena that are fundamentally different from those applied in conventional extraction techniques. These novel processes can produce essential oils in concentrate form, free from any residual solvents, contaminants, or artifacts.

So far, the role of relevant SFME methods has not reached the degree of maturity of conventional methods. However, more and more studies on these up-to-date techniques have proved the usefulness of microwaves in separation technology and their potential for developing scientifically-sound extraction procedures, and their advantages concerning yield and composition, with better selectivity and quality of extracts, and finally being helpful in creating a clean, safe environment. 


\section{Acknowledgements}

This study was funded under the European Alcotra program Eco-extraction Transfrontaliere 2011-2013 between France (PACA) and Italy (Piemonte).

\section{References}

[1] S. Armenta, S. Garrigues, M. de la Guardia, Trends Anal. Chem. 27 (2008) 497.

[2] R.M. Smith, J. Chromatogr. A 1000 (2003) 3.

[3] K. Ridgway, S.P.D. Lalljie, R.M. Smith, J. Chromatogr. A 1153 (2007) 36.

[4] Y. Picó, Trends Anal. Chem. 43 (2013) 84.

[5] Y. Li, A.S. Fabiano-Tixier, V. Tomao, G. Cravotto, F. Chemat, Ultrason. Sonochem. 20 (2013) 12.

[6] F. Chemat, Zill-e-Huma, M.K. Khan, Ultrason. Sonochem. 18 (2011) 813.

[7] E. Reverchon, J. Supercrit. Fluid 10 (1997) 1.

[8] S.A. Rezzoug, C. Boutekedjiret, K. Allaf, J. Food Eng. 71 (2005) 9.

[9] T. Allaf, V. Tomao, K. Ruiz, F. Chemat, Ultrason. Sonochem. 20 (2013) 239.

[10] A. Brachet, S. Rudaz, L. Mateus, P. Christen, J.L. Veuthey, J. Sep. Sci. 24 (2001) 865.

[11] M.Z. Ozel, F. Gogus, A.C. Lewis, Food Chem. 82 (2003) 381.

[12] F. Chemat, M. Lucchesi, in: A. Loupy (Editor), Microwaves in Organic Synthesis, Wiley-VCH, Weinheim, Germany, 2006, p. 959.

[13] M.A. Ferhat, B.Y. Meklati, J. Smadja, F. Chemat, J. Chromatogr. A 1112 (2006) 121.

[14] M.E. Lucchesie, J. Smadja, S. Bradshaw, W. Louw, F. Chemat, J. Food Eng. 79 (2007) 1079.

[15] N. Sahraoui, M. Abert Vian, I. Bornard, C. Boutekedjiret, F. Chemat, J. Chromatogr. A 1210 (2008) 229.

[16] N. Sahraoui, M. Abert Vian, M.E. Maataoui, C. Boutekedjiret, F. Chemat, Innov. Food Sci. Emerg. Technol. 12 (2011) 163.

[17] A. Farhat, A.S. Fabiano-Tixier, M.E. Maataoui, J.F. Maingonnat, M. Romdhane, F. Chemat, Food Chem. 125 (2011) 255-261.

[18] F. Chemat, M.E. Lucchesi, J. Smadja, L. Favretto, G. Colnaghi, F. Visinoni, Anal. Chim. Acta 555 (2006) 157.

[19] M. Bendahou, A. Muselli, M. Grignon-Dubois, M. Benyoucef, J.M. Desjobert, A.F. Bernardini, J. Costa, Food Chem. 106 (2008) 132.

[20] M. Abert Vian, F. Chemat, J. Smadja, J. Chromatogr. A 1043 (2004) 323.

[21] M.A. Ferhat, B.Y. Meklati, F. Visinoni, M. Abert Vian, F. Chemat, Chim. Oggi 26 (2008) 48.
[22] O.O. Okoh, A.P. Sadimenko, A.J. Afolayan, Food Chem. 120 (2010) 308.

[23] B. Bayramoglu, S. Sahin, G. Sumnu, J. Food Eng. 88 (2008) 535.

[24] L. Perreux, A. Loupy, Tetrahedron 57 (2001) 9199.

[25] F. Chemat, J. Smadja, M.E. Lucchesie, Eur. Patent 1439218 (2004) B1.

[26] F. Chemat, M.E. Lucchesie, J. Smadja, US Patent 0187340 (2004) A1.

[27] Z. Wang, L. Ding, T. Li, X. Zhou, L. Wang, H. Zhang, L. Liu, Y. Li, Z. Liu, H. Wang, H. Zeng, H. He, J. Chromatogr. A 1102 (2006) 11.

[28] Z. Wang, L. Wang, T. Li, X. Zhou, L. Ding, Y. Yu, A. Yu, H. Zhang, Anal. Bioanal. Chem. 386 (2006) 1863.

[29] Y. Zhai, S. Sun, Z. Wang, J. Cheng, Y. Sun, L. Wang, Y. Zhang, H. Zhang, A. Yu, J. Sep. Sci. 32 (2009) 3544.

[30] P. Mengal, B. Mompon, Int. Patent WO 94 (26853) (1994).

[31] P. Mengal, B. Mompon, Eur. Patent 698076 (1996) B1.

[32] P. Mengal, D. Behn, M.B. Gill, B. Mompon, Parfums Cosmétiques Aromes 114 (1993) 66.

[33] P. Mengal, B. Mompon, Can. Patent CA 2161127 (1994).

[34] T. Michel, E. Destandau, C. Elfakir, Food Chem. 126 (2011) 1380.

[35] M. Abert Vian, X. Fernandez, F. Visinoni, F. Chemat, J. Chromatogr. A 1190 (2008) 14.

[36] Zill-e-Huma, M. Abert-Vian, J.F. Maingonnat, F. Chemat, J. Chromatogr. A 1216 (2009) 7700.

[37] Zill-e-Huma, M. Abert-Vian, M. Elmaataoui, F. Chemat, J. Food Eng. 105 (2011) 351.

[38] A. Farhat, A.S. Fabinao-Tixier, F. Visinoni, M. Romdhane, F. Chemat, J. Chromatogr. A 1217 (2010) 7345.

[39] C. Deng, X. Xu, N. Yao, N. Li, X. Zhang, Anal. Chim. Acta 556 (2006) 289.

[40] N. Bousbia, M. Abert-Vian, M.A. Ferhat, E. Peticolas, B.Y. Meklati, F. Chemat, Food Chem. 14 (2009) 355.

[41] N. Bousbia, M. Abert-Vian, M.A. Ferhat, B.Y. Meklati, F. Chemat, J. Food Eng. 90 (2009) 409.

[42] M. Zill-e-Huma, A.S. Abert-Vian, M. Fabiano-Tixier, O. Elmaataoui, F. Dangles, Chemat, Food Chem. 127 (2011) 1472.

[43] S. Périno-Issartier, Zill-e-Huma, M. Abert-Vian, F. Chemat, Food Bioprocess Technol. 4 (2010) 1020.

[44] C.G. Grigoras, E. Destandau, S. Zubrzycki, C. Elfakir, Sep. Purif. Technol. 100 (2012) 51.

[45] F. Chemat, G. Cravotto, Microwave-Assisted Extraction for Bioactive Compounds, Springer US, New York, USA, 2013. 